\title{
Numerical simulation and comparative analysis of pressure drop estimation in horizontal and vertical slurry pipeline
}

\author{
O. Parkash ${ }^{1,2}$, A. Kumar ${ }^{2}$ and B. S. Sikarwar ${ }^{3}$ \\ ${ }^{1}$ Faculty of Mechanical Engineering, Amity University Haryana, Gurgaon, 122413, India \\ Phone: +91-98134-61935 \\ 2 Faculty of Mechanical Engineering, J C Bose YMCA University, Faridabad, 121006, India \\ ${ }^{3}$ Faculty of Mechanical Engineering, Amity University Uttar Pradesh, Noida, 201313, India
}

\begin{abstract}
Transportation of solids with water as a carrier in the form of slurry through long length pipelines is widely used by many industries and power plants. The transportation of slurry through vertical pipeline is a challenging task and require modification to overcome the pressure loss and power consumption requirements. In this perspective, numerical simulation of threedimensional horizontal slurry pipeline (HSPL) and vertical slurry pipeline (VSPL) carrying glass beads solid particulates of spherical diameter $440 \mu \mathrm{m}$ and density $2,470 \mathrm{~kg} / \mathrm{m}^{3}$ is carried out. The $3 \mathrm{D}$ computational model for horizontal and vertical slurry pipeline is developed for a pipe of 0.0549 $\mathrm{m}$ diameter and analyzed in available commercial software ANSYS Fluent 16 . The simulation is conducted by using Eulerian multiphase model with RNG $k-\varepsilon$ turbulence closure at solid concentration range $10-20 \%$ (by volume) for mean flow velocities ranging from 1-4 ms-1. It is found that the pressure drop rises for both HSPL and VSPL with escalation in mean flow velocity and solid concentration. The predicted pressure drop in VSPL is found to follow the same pattern as with HSPL but higher in magnitude for all chosen velocity and solid concentration range. The obtained results of predicted pressure drop in HSPL are validated with the available experimental data in the literature. A parametric study is conducted with the aim of visualizing and understanding the slurry flow behavior in HSPL and VSPL. Finally, the results of solid concentration contour, velocity contour, solid concentration profiles, velocity profiles and pressure drop are predicted for both the slurry pipelines.
\end{abstract}

ARTICLE HISTORY

Revised: 14 $4^{\text {th }}$ Nov 2019

Accepted: $16^{\text {th }}$ Nov 2019

\section{KEYWORDS}

$3 D$ horizontal slurry

pipeline;

$3 D$ vertical slurry pipeline;

Eulerian two-phase model; slurry concentration; velocity distribution; pressure drop.

\section{INTRODUCTION}

The slurry transportation has been utilized by different enterprises and power plant since a very long while. Slurry transport through long length pipelines is utilized by numerous ventures since it has a few points of interest, for example, no contamination, no traffic, power consumption and constant conveyance and so forth. Solids like coal ash, iron metal ore, copper, zinc tailing, rock, and concrete material shipped with water as slurry at the ideal desired conveyance area by numerous enterprises. The slurry transportation framework comprises of horizontal pipes, vertical pipes and pipe bend at intermediate stages for the persistent conveyance of the solids at the desired location. The solid concentration leads to motive i.e. erosion wear, damage and deterioration in pipelines and pumps.

In the literature, numerous research experiments are available to assess and evaluate the different slurry flow parameters like pressure gradient, velocity and concentration measurement and so on. Matousek [1] in a laboratory experiment analyzed sand flow pattern in a pipe of $0.105 \mathrm{~m}$ diameter at three unique geometries viz. horizontal, vertical and $-35^{\circ}$ descending pipes. Kraft [2] resented various methods to observe the slurry flow trends in a slurry pipeline. Kaushal et al. [3] experimented the effect of near wall lift on solid particles in a pipe of 0.0549 m diameter and determined the effect of slip velocity on pressure drop, and observed that effect is more at higher velocity as compared to low velocity. Kumar et al. [4] used two layer and Karabelas model, and studied the effect of pressure drop and solid concentration on bimodal slurries. Matousek [5] investigated the effect of pressure on coarse, medium and fine sand particles flowing in a vertical pipeline. The findings show that the effect of lift forces on medium size sand particles is greater in comparison to the coarse and fine size particles. The sand slurry simulation the usage of algebraic slip model growth of numerous constraints at the entrance vicinity of the pipeline is achieved by way of Lin and Ebadian [6]. Chandel et al. [7-8] examined the pressure drop and rheological characteristics for fly ash slurries and observed no settling of slurry at all tested data. Further, he proceeded with the study on pilot plant test loop with/without additive in the slurry and found a dip in pressure drop on addition of additives. Moreover, Naik et al. [9] considered the rheological qualities by adding the cationic and counter ion and it was observed that the addition of cationic and counter ion brings about decrease of surface tension, improvement in wetting/spreading properties and upgrade in suspension stability of solid particulates. Senapati et al. [10] utilized the power law fluid and explored the impact of fly-slag slurry on friction. 
Thereafter, the numerical simulation of slush nitrogen in a horizontal pipeline is done by Jiang and Zhang [11] and found that 2-D multiphase model brings about less computational time when compared with 3-D models. Kaushal et al. [12] utilized Mixture model and Eulerian model to anticipate the slurry characteristics of glass beads particulates, and found that Eulerian model gives better outcomes for pressure drop when compared with the mixture model. Afterward, they tested fly ash slurry stream at high concentration on pilot plant test loop, and got the rheological attributes of slurry, and optimum convergences of fly-ash slurries is observed to be $65 \%$ (by weight) based on specific energy consumptions [13].

Nabil et al. [14] simulated sand-water slurry flow characteristics in a pipeline for three exclusive particle sizes of 0.2 , 0.7 and $1.4 \mathrm{~mm}$ in a velocity range of 0.5 to $5 \mathrm{~ms}^{-1}$. The discovering demonstrates that the irregularity in slurry flow ascends with increment in particulates size because of gravitational effect. Silva et al. [15] considered the settling behavior and effect of flow velocity on slurry flow. Gopaliya and Kaushal [16] studied the effect of various grain size utilizing RNG k- $\varepsilon$ turbulence model in horizontal pipeline on slurry flow attributes and found that the pressure drop ascends with growth in grain size at all efflux concentration. Pani et al. [17] studied the additives effects on the coal ash slurry. Assefa and Kaushal [18] tested the rheological characteristics of fly ash slurry in the bottom ash slurry and found that the acquired rheological attributes with low yield stress and velocity. Swamy et al. [19] did the numerical simulation of sand water stream utilizing Eulerian two-phase model in a horizontal pipeline and demonstrates that the large particles show heterogeneous flow. Wu et al. [20] built up a model so as to investigate the flow attributes of the cement, coal ash, fly ash and fluid. Messa and Malavasi [21] picked 0.050-0.200 m pipe diameter for 90-640 $\mu \mathrm{m}$ particle size and introduced a novel two-phase model for simulating the liquid solid slurry in horizontal pipeline. Gopaliya and Kaushal [22] simulated the sand water slurry utilizing Eulerian multiphase model with $\mathrm{k}-\varepsilon$ turbulence closure in a pipe of $0.263 \mathrm{~m}$ diameter and experimented the symmetric and asymmetric nature of velocity profile for fine and coarser particulates respectively. Ofei and Ismail [23] conducted the simulation for various particle sizes ranging from 90-270 $\mu \mathrm{m}$ at different solid concentrations range $10-40 \%$, using Eulerian-Eulerian two-phase model with $\mathrm{k}-\varepsilon$ turbulence closure in a horizontal pipeline. The study demonstrates that frictional pressure drop decreases with increment in particle sizes. Peng and Cao [24] used Eulerian Lagrangian strategy to examine the flow characteristics in pipe bend. The experimental research on bi modal slurry consists of fly ash and silica particulates has been carried out by Kaushal et al. [25].The study is carried out for six silica sand/fly ash in the velocity range of $1.78-3.56 \mathrm{~ms}^{-1}$ for $75-450 \mu \mathrm{m}$ particle sizes at efflux concentration ranging $8.82 \%-16.28 \%$ (by volume). It was observed that the bi-modular slurry experiences less pressure drop as compared with the mono scatter silica molecule.

Assefa and Kaushal [26] presented a new empirical model using non-linear least square curve fitting and optimization method to investigate the viscosity profile for multi size particulates Bingham slurry at higher values of concentration ( $>50 \%$, by weight). Melorie and Kaushal [27] experimented that the addition of hydrated lime as a chemical additives in iron ore slurry escalates the yield stress at different solid concentrations. Naveh et al. [28] found that pressure drop is a strong function of Archemede's number by executing the distinctive turbulence model for diluted slurry in a horizontal pipe. Singh et al. [29] completed the experimental and numerical simulation of sand water stream and observed that the pressure drop rises non-linearly with escalation in velocity and solid concentrations. Sultan et al. [30] examined the pressure loss through the annular pipe utilizing Eulerian two-phase model with Reynold stress model turbulence closure. Tran et al. [31] simulated the air and water flow through T-junction and reported the effect of diameter ratio and superficial velocities on phase split. Parkash et al.[32] reported the pressure drop through horizontal slurry pipeline at Prandtl number, $\operatorname{Pr}-5.83$. Ahmed et al. [33] predicted the slurry flow characteristics for $125-\mu \mathrm{m}$ particulates slurry through the horizontal pipeline using granular Eulerian model with RNG k- $\varepsilon$ turbulence closure. Parkash and Arora Bouaffane and Talbi [34] carried out the thermal simulation of fluid flow through annular pipe completely filled with porous material and studied the local difference temperature and convective heat transfer coefficient. The recent work for obtaining the flow characterstics in the fully developed region through slurry pipeline is reported by Parkash and Ahmed [35-37].

In the literature, numerous exploratory and numerical studies has been accounted for the parametric designing of high concentration slurry pipeline for glass beads, fly ash, bottom ash and silica sand and so on. It is revealed that there is limited literature available for the simulation of vertical slurry pipelines and it is still a challenging task to overcome the pressure loss and power consumption requirements. Moreover, the comparison of pressure drop between vertical and horizontal slurry pipeline is also not available in the literature. However, in real time it is miles quite complicated and hard to layout and fabricate the experimental set up as it require long time and higher expenses. Therefore, it is observed that the experimental determination of velocity, pressure drop and concentration profile for different pipe geometry at their different location is troublesome and tedious. Therefore, a parametric study is carried out to know the impact of pipe geometry on slurry flow characteristics. Henceforth, computational fluid dynamics possess ample scope and capability for evaluating above-mentioned parameters at any cross-section of the pipe geometry.

In this paper, a computational model for VSPL and HSPL is developed in order to find out the pressure drop by employing Eulerian multiphase model with RNG k- $\varepsilon$ turbulence closure. The simulation for both the pipe geometry has been completed for solid concentration range of $10 \%$ to $20 \%$ (by volume) with wide velocity range of $1-4 \mathrm{~ms}^{-1}$. The validation of the developed computational model is done by comparing the simulated results with the available experimental data for HSPL and it is discovered that the proposed model provides progressively meticulous and precise outcomes. 


\section{MATHEMATICAL MODEL}

The simulation work for both VSPL and HSPL is done by utilizing Eulerian two-phase model with RNG K- $\varepsilon$ turbulence closure. The outline geometry for VSPL and HSPL is shown in the Figure 1(a) and (b) respectively. The governing equations used for the turbulence closure of glass beads slurry flow are as given below.

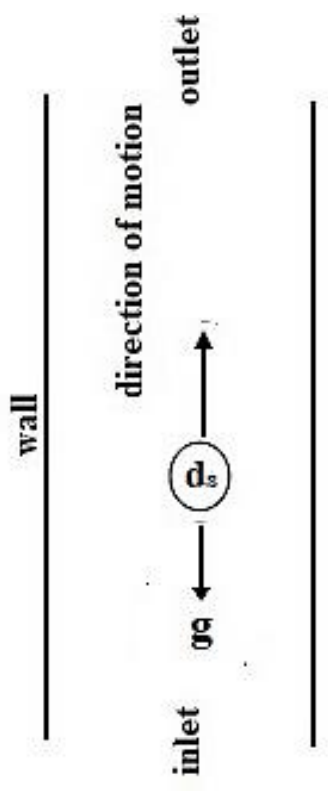

(a)

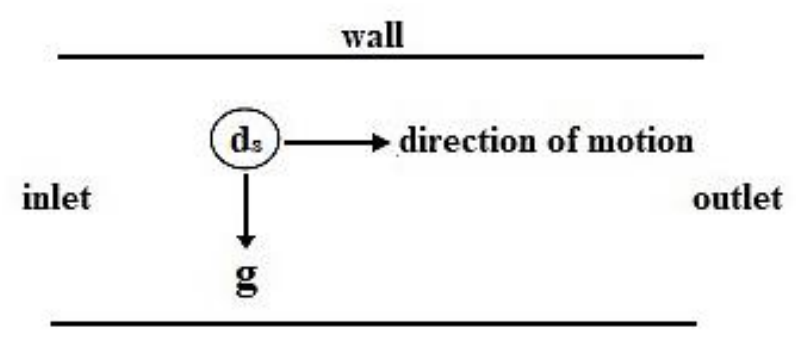

(b)

Figure 1. Outline geometry for (a) VSPL and (b) HSPL.

\section{Eulerian Model}

Eulerian model is used as it is the effective model to tackle the continuity and momentum equation for each phase and coupling between the phases is accomplished through pressure and interexchange coefficients. In Eulerian model, the slurry blend supposed to be comprise of solid $\left(\alpha_{s}\right)$ and liquid $\left(\alpha_{f}\right)$ phases i.e. $\alpha_{s}+\alpha_{f}=1$. In the present model, granular flow properties are attaining from kinetic theory applications. The solid particles in the slurry flow subjected to the following forces i.e. Static/solid pressure gradient $\left(\nabla P / \nabla P_{S}\right)$, viscous force $\left(\nabla \cdot \overline{\overline{\tau_{f}}}\right)$, where $\overline{\overline{\tau_{f}}}$ is the viscous stress tensor for fluid phase and body forces $(\rho \vec{g})$, where $\rho$ is the mass density in $\mathrm{kg} / \mathrm{m}^{3}$ and $\vec{g}$ is the acceleration due to gravity (m/s ${ }^{2}$ ), Lift/virtual forces and forces due to phase velocities difference $\left(K_{s f}\left(\vec{v}_{s}-\vec{v}_{l}\right)\right)$, where $K_{s f}$ represents the inter-phase momentum exchange coefficient and $\overrightarrow{v_{s}}$ and $\overrightarrow{v_{f}}$ are velocity of solid phase and liquid phase respectively. The virtual mass and lift coefficient $\left(C_{v m} / \mathrm{C}_{\mathrm{L}}\right)$ is assumed as 0.5 in the present study. The two phase Navier-stokes equation has been solved to knowing the velocity and pressure field in the domain of $0.0549 \mathrm{~m}$ diameter pipe. The solid particulates in the fluid domains are assumed of spherical in shape and fluidic in nature.

\section{Governing Equations}

The governing equations used for the turbulent flow of glass beads slurry flow are:

\section{Continuity Equation}

$$
\nabla \cdot\left(\alpha_{t} \rho_{t} \vec{v}_{t}\right)=0
$$

here, $t$ can be considered as $l$ or $s$.

\section{Momentum Equations for Fluid and Solid phases}

For liquid phase:

$$
\left[\begin{array}{l}
\nabla \cdot\left(\alpha_{l} \rho_{l} \vec{v}_{l} \vec{v}_{l}\right)=-\alpha_{l} \nabla P+\nabla \cdot\left(\overline{\overline{\tau_{l}}}+\overline{\overline{\tau_{f, l}}}\right)+\alpha_{l} \rho_{l} \vec{g}+K_{s l}\left(\vec{v}_{s}-\vec{v}_{l}\right)+C_{v m} \alpha_{s} \rho_{l}\left(\vec{v}_{s} \cdot \nabla \vec{v}_{s}-\vec{v}_{l} \cdot \nabla \vec{v}_{l}\right) \\
+C_{L} \alpha_{s} \rho_{l}\left(\vec{v}_{l}-\vec{v}_{s}\right) \times\left(\nabla \times \vec{v}_{l}\right)
\end{array}\right]
$$


For solid phase:

$$
\left[\begin{array}{l}
\nabla .\left(\alpha_{s} \rho_{s} \vec{v}_{s} \vec{v}_{s}\right)=-\alpha_{s} \nabla P-\nabla P_{s}+\nabla \cdot\left(\overline{\overline{\tau_{s}}}+\overline{\overline{\tau_{f, l}}}\right)+\alpha_{s} \rho_{s} \vec{g}+K_{l s}\left(\vec{v}_{l}-\vec{v}_{s}\right)+C_{v m} \alpha_{s} \rho_{l}\left(\vec{v}_{l} \cdot \nabla \vec{v}_{l}-\vec{v}_{s} \cdot \nabla \vec{v}_{s}\right) \\
+C_{L} \alpha_{s} \rho_{l}\left(\vec{v}_{s}-\vec{v}_{l}\right) \times\left(\nabla \times \vec{v}_{l}\right)
\end{array}\right]
$$

here, $\overline{\overline{\tau_{f, l}}}$ is the Reynolds stress tensor, whereas $\overline{\overline{\tau_{s}}}$ and $\overline{\overline{\tau_{l}}}$ are the viscous stress tensors for solid and liquid phase respectively and are given by:

$$
\overline{\overline{\tau_{s}}}=\left[\alpha_{s} \mu_{s}\left(\nabla \vec{v}_{s}+\nabla \vec{v}_{s}^{f r}\right)+\alpha_{s}\left(\lambda_{s}-\frac{2}{3} \mu_{s}\right) \nabla \cdot \vec{v}_{s} \overline{\bar{I}}\right]
$$

and,

$$
\overline{\overline{\tau_{l}}}=\left[\alpha_{l} \mu_{l}\left(\nabla \vec{v}_{l}+\nabla \vec{v}_{l}^{f r}\right)\right]
$$

here, superscript ' $f r$ ' above the velocity vector represents the transpose and $\overline{\bar{I}}$ represents the identity tensor and $\lambda_{s}$ indicates the bulk viscosity of the solid as given below:

$$
\lambda_{s}=\left[\frac{4}{3} \alpha_{s} \rho_{s} d_{s} g_{o, s s}\left(1+e_{s s}\right)\left(\frac{\Theta_{s}}{\pi}\right)^{\frac{1}{2}}\right]
$$

$d_{s}$ is the diameter of the particulates which is taken as $440 \mu \mathrm{m}$ in the present study. $g_{o, s s}$ is the radial distribution function which is defined as:

$$
g_{o, s s}=\left[1-\left(\frac{\alpha_{s}}{\alpha_{s, \max }}\right)^{\frac{1}{3}}\right]^{-1}
$$

here, $\alpha_{s, \max }$ is the static settled concentration, $\Theta_{s}$ is the granular temperature, $e_{s s}$ is the restitution coefficient and $\mu_{l}$ is the shear viscosity of liquid.

Solid shear viscosity $\mu_{s}$ is defined as:

$$
\mu_{s}=\mu_{s, c o l}+\mu_{s, k i n}+\mu_{s, l r}
$$

here, $\mu_{s, c o l}, \mu_{s, k i n}$ and $\mu_{s, l r}$ are collisional, kinetic and frictional viscosities respectively. These can be defined as:

$$
\begin{gathered}
\mu_{s, c o l}=\frac{4}{5} \alpha_{s} \rho_{s} d_{s} g_{o, s s}\left(1+e_{s s}\right)\left(\frac{\Theta_{s}}{\pi}\right)^{\frac{1}{2}} \\
\mu_{s, l r}=\frac{P_{s} \sin \varphi}{2 \sqrt{I_{2 D}}} \\
\mu_{s, k i n}=\left[\frac{\alpha_{s} d_{s} \rho_{s} \sqrt{\Theta_{s} \pi}}{6\left(3-e_{s s}\right)}\left[1+0.4\left(1+e_{s s}\right)\left(3 \mathrm{e}_{s s}-1\right) \alpha_{s} g_{o, s s}\right]\right]
\end{gathered}
$$

$I_{2 D}$ is another invariant of the deviatory strain rate tensor defined for solid phase, $\varphi$ is the internal friction angle considered $30^{\circ}$ in the present calculations and $P_{s}$ indicates the solid pressure as given below:

$$
P_{s}=\left[\alpha_{s} \rho_{s} \Theta_{s}+2 \rho_{s}\left(1+e_{s s}\right) \alpha_{s}^{2} g_{o, s s} \Theta_{s}\right]
$$


$K_{s l}$ represents the inter-phase momentum exchange coefficient defined as:

$$
K_{s l}=K_{l s}=\frac{3}{4} \frac{\alpha_{s} \alpha_{l} \rho_{l}}{V_{r, s}^{2} d_{s}} C_{D}\left(\frac{\operatorname{Re}_{s}}{V_{r, s}}\right)\left|\vec{v}_{s}-\vec{v}_{l}\right|
$$

$C_{D}$ represents the drag coefficient defined by:

$$
C_{D}=\left(0.63+4.8\left(\frac{\mathrm{Re}_{s}}{V_{r, s}}\right)^{\frac{-1}{2}}\right)^{2}
$$

$R e_{f}$ is the relative Reynolds number for the liquid and solid phase and defined as:

$$
\operatorname{Re}_{f}=\frac{\rho_{l} d_{s}\left|\vec{v}_{s}-\vec{v}_{l}\right|}{\mu_{l}}
$$

$V_{r, s}$ represents the terminal velocity of the solid phase.

\section{Wall Function}

The standard wall function has been employed for both the pipe geometry. The chosen wall function provides more accurate and precise results for both solid and liquid phases using Eulerian two-phase model.

\section{COMPUTATIONAL DOMAIN AND GRID INDEPENDENT TEST}

The computational mesh for both 3D slurry pipeline of length $3.8 \mathrm{~m}$ and diameter $0.0549 \mathrm{~m}$ is generated in ANSYS 16. The pipe length considered for the computational domain is adequately long fully developed flow as it satisfies the criteria of more than 50 times diameter of the pipeline. The computational geometry contains $462 \mathrm{~K}$ hexahedral and quad type mesh elements. The grid independent test is carried out by using distinctive mesh geometry containing $154 \mathrm{~K}$, 243 $\mathrm{K}, 382 \mathrm{~K}, 462 \mathrm{~K}$ and $522 \mathrm{~K}$ hexahedral/quad elements at $C_{v f}=40 \%$ and $V_{m f}=5 \mathrm{~ms}^{-1}$. It is seen that the outcomes for solid concentration and solid velocity are not changing for the grid geometry containing $462 \mathrm{~K}$ and $522 \mathrm{~K}$ mesh elements. The mean flow velocity for different grid geometry is depicted in Figure 2(b). Hence, a grid geometry comprises of 462 $\mathrm{K}$ elements is preferred for simulation of slurry flow as shown in the Figure 2(a).

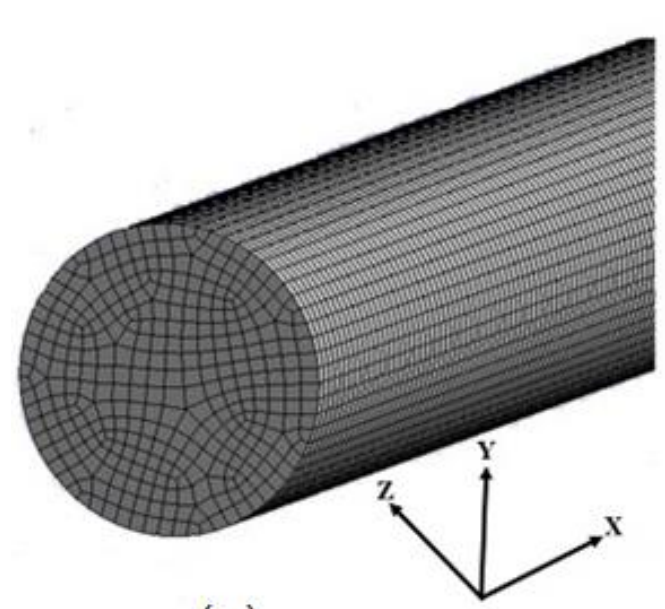

(a)

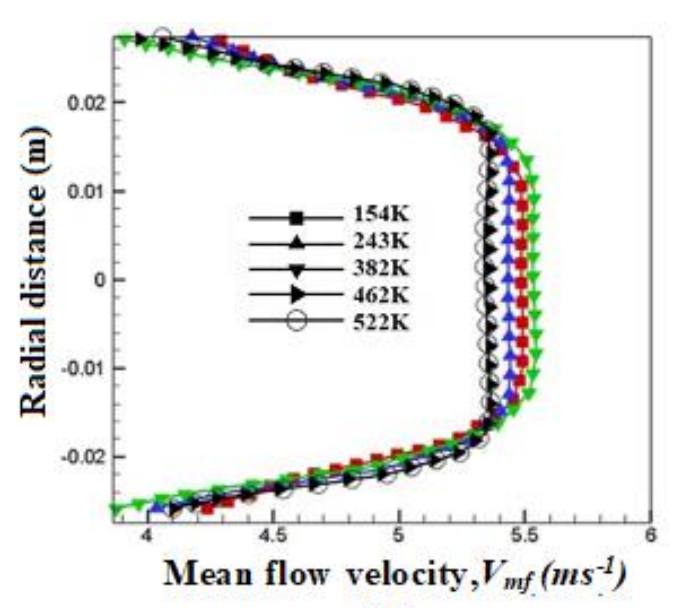

(b)

Figure 2. (a) Grid geometry and (b) Mean flow velocity profile at $C_{v f}=40 \%$ and $V_{m f}=5 \mathrm{~ms}^{-1}$. 


\section{Flow chart}

Figure 3 depicts the flow chart for the simulation process as shown below.

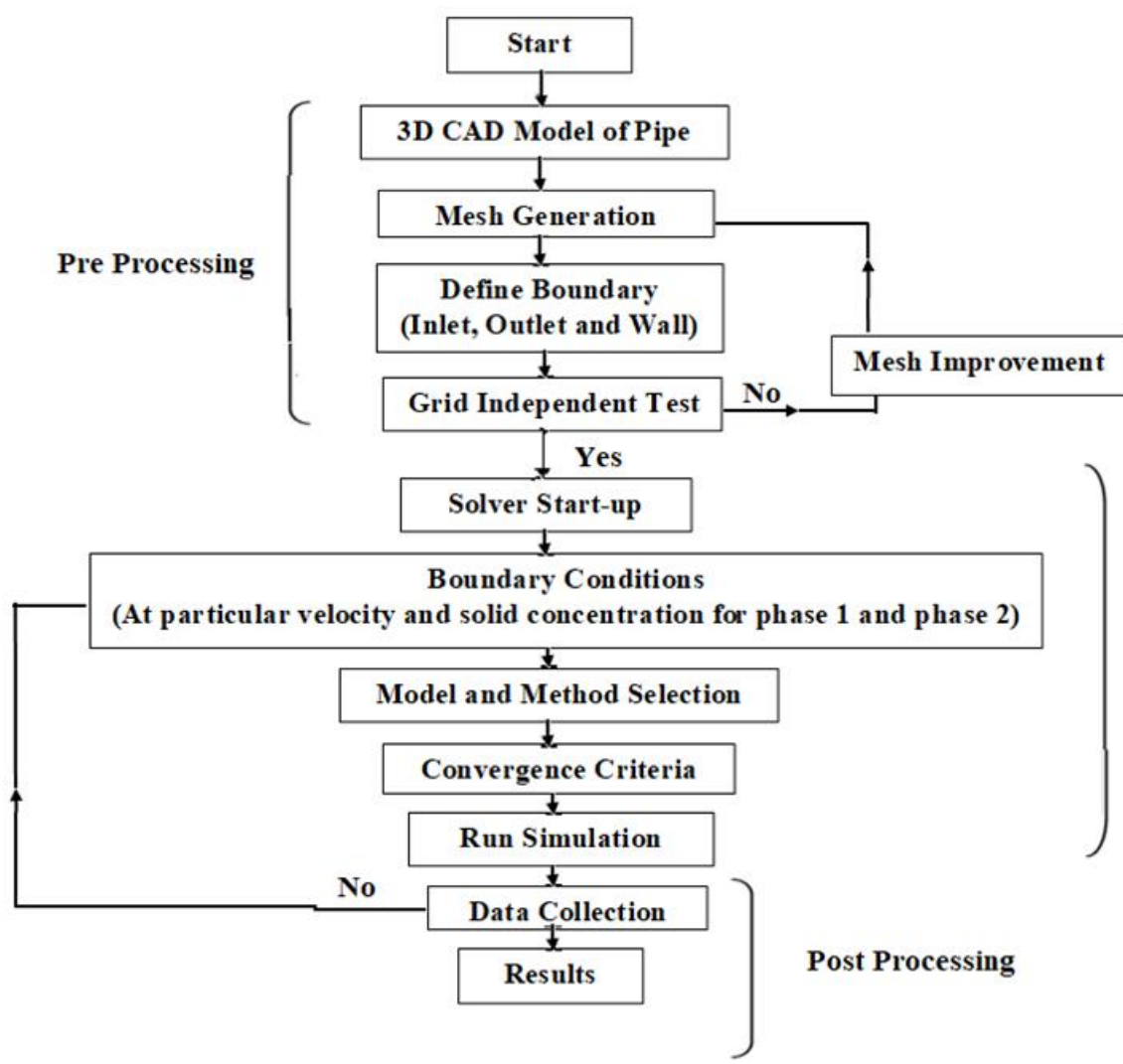

Solver

Figure 3. Simulation flow chart.

\section{Boundary Conditions}

The 3D slurry pipeline geometry comprises of three faces viz. inlet, outlet and wall boundaries to accomplish the computational results. The boundary condition at inlet face of the pipe is applied at particular velocity and solid volume fraction whereas pressure outlet is applied at outlet face of the pipe. The no slip condition has been considered at the wall boundaries. In addition, the roughness constant of the wall is assumed to be 0.5 in the present study.

\section{Solution Strategies and Convergence Criteria}

The fluid/solid phase continuity, momentum, turbulence kinetic energy equations are solved by using second order upwind scheme. This course of action offers high precision, reliability and converging of the solutions. The convergence criteria is set to 0.001 times the initial residual values for every constraint viz. mass, turbulent kinetic, velocity, dissipation energy and volume fractions. Straight forward algorithm is used to accomplish the coupling among velocity and pressure linked equations. The other solution strategies and convergence factors values are: pressure -0.3 , momentum -0.5 , volume fraction -0.5 , turbulent viscosity -0.8 , turbulent kinetic/dissipation energies -0.8 .

\section{COMPUTATIONAL RESULTS}

\section{HSPL Solid Concentration Contours}

Figure 4 depicts the solid concentration distribution at the outlet of the HSPL at solid concentration, $C_{v f}=10 \%$ (by volume) for different velocity range, $V_{m f}=1-4 \mathrm{~ms}^{-1}$. It has been discovered that at low mean flow velocity, $V_{m f}=1 \mathrm{~ms}^{-1}$ the solids tend to settled down at pipe bottom as depicted in the Figure 4(a). However, as the velocity increases to $2 \mathrm{~ms}^{-1}$ the solids particulates shifts away from the pipe bottom as portrayed in the Figure 4(b). Furthermore, as the velocity increases beyond $2 \mathrm{~ms}^{-1}$ the solid particulates disperse in the lower half section of the pipeline for the mean flow velocity range, $V_{m f}=3-4 \mathrm{~ms}^{-1}$ as portrayed in the Figure 3(c-d). The similar likewise effects can be seen at $C_{v f}=20 \%$ for chosen mean flow velocity range, $V_{m f}=1-4 \mathrm{~ms}^{-1}$ as depicted in the Figure 5(a-d). However, the fluidised bed thickness in the lower half section of the pipeline is more in case of Figure 5 as compared to the Figure 4 due to increased concentration. The shifting of the solid particulates away from the pipe bottom occurs due to increase in velocity, which results the increment in momentum exchange between solid-solid particulates, solid-wall interaction and near wall lift force. 


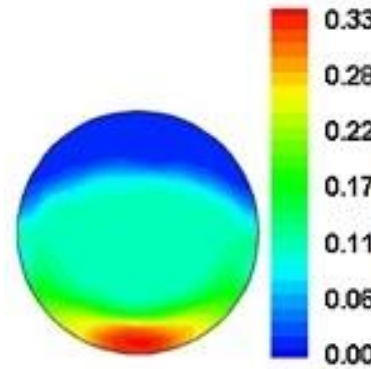

(a)

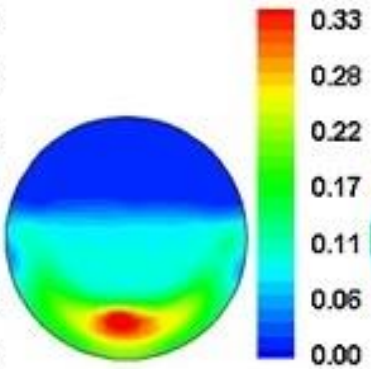

(b)

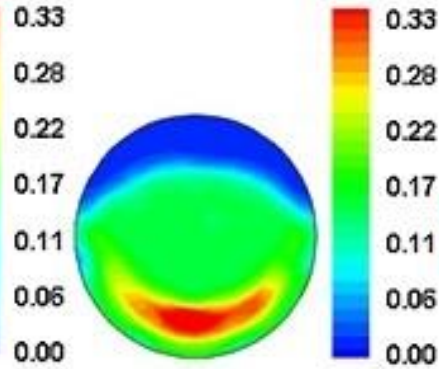

(c)

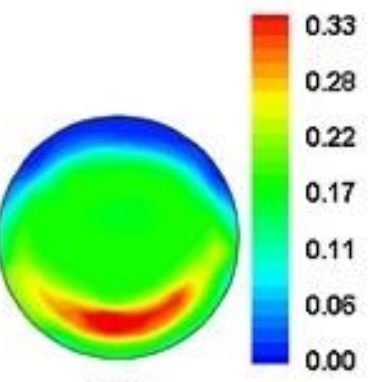

(d)

Figure 4. HSPL solid concentration contours at $C_{v f}=10 \%$, (a) $V_{m f}=1 \mathrm{~ms}^{-1}$, (b) $V_{m f}=2 \mathrm{~ms}^{-1}$, (c) $V_{m f}=3 \mathrm{~ms}^{-1}$, and (d) $V_{m f}=4 \mathrm{~ms}^{-1}$.

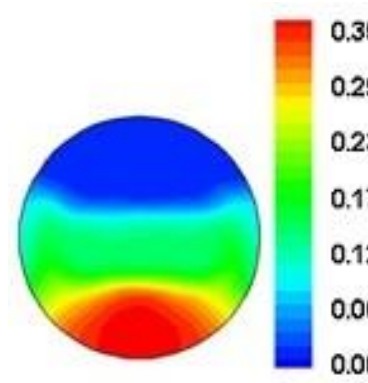

(a)

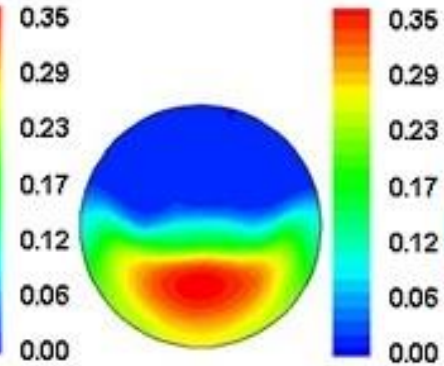

(b)
0.00

Figure 5. HSPL solid concentration contours at $C_{v f}=20 \%$, (a) $V_{m f}=1 \mathrm{~ms}^{-1}$, (b) $V_{m f}=2 \mathrm{~ms}^{-1}$, (c) $V_{m f}=3 \mathrm{~ms}^{-1}$, and (d) $V_{m f}=4 \mathrm{~ms}^{-1}$.

\section{HSPL Velocity Contours}

Figure 6 depicts the solid velocity contours at the outlet of HSPL at solid concentration, $C_{v f}=10 \%$ (by volume) for different mean flow velocity range, $V_{m f}=1-4 \mathrm{~ms}^{-1}$. It has been found that the solid exhibits maximum velocity at the center of the pipeline at all velocity range and solid efflux concentration. At low mean flow velocity, $V_{m f}=1-2 \mathrm{~ms}^{-1}$ the velocity contours are asymmetrical about the pipe center as depicted in the Figure 6(a-b). However as the mean flow velocity increases to 3-4 $\mathrm{ms}^{-1}$, the velocity winds up balanced about the center of the pipe line as illustrated in the Figure $6(\mathrm{c}-\mathrm{d})$. The comparative effects can likewise be observed at $C_{v f}=20 \%$ for chosen mean flow velocity range, $V_{m f}=1-4$ $\mathrm{ms}^{-1}$ as depicted in the Figure 7(a-d). However, at low velocity range, $V_{m f}=1-2 \mathrm{~ms}^{-1}$ the velocity contours at $C_{v f}=20 \%$ are more asymmetrical as compared to the velocity contour at $C_{v f}=10 \%$ as depicted in the Figure 7(a-b) and 6(a-b), respectively. The evenness of the velocity contours increases with escalation in velocity and solid concentration. The escalation in velocity and solid concentrateon enhance the turbulence blending and consequently escalates the dispersal of solid particulates in the pipeline.

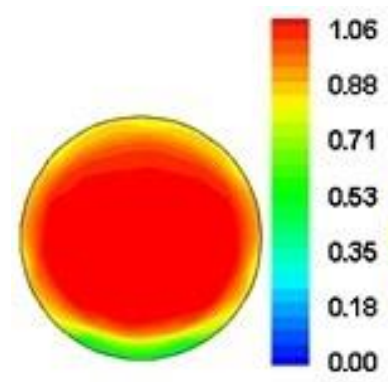

(a)

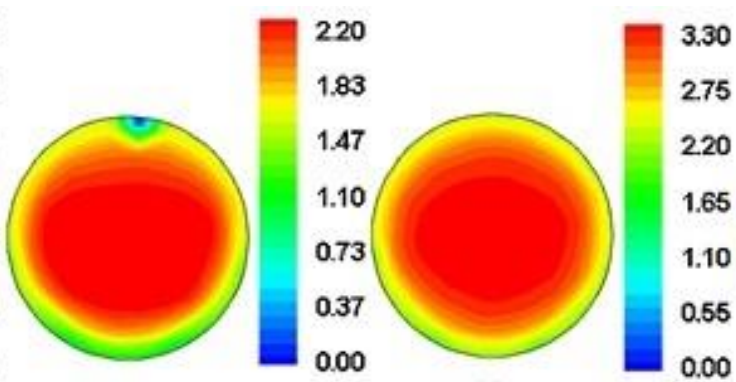

(b) (c)

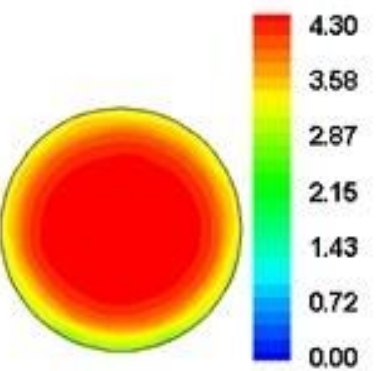

(d)

Figure 6. HSPL velocity contours at $C_{v f}=10 \%$, (a) $V_{m f}=1 \mathrm{~ms}^{-1}$, (b) $V_{m f}=2 \mathrm{~ms}^{-1}$, (c) $V_{m f}=3 \mathrm{~ms}^{-1}$, and (d) $V_{m f}=4 \mathrm{~ms}^{-1}$. 


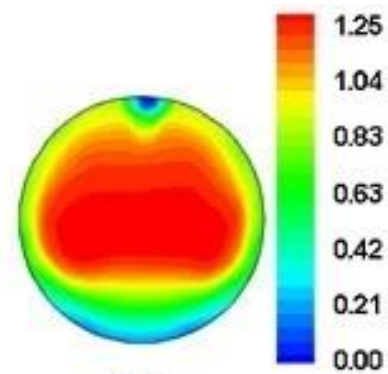

(a)

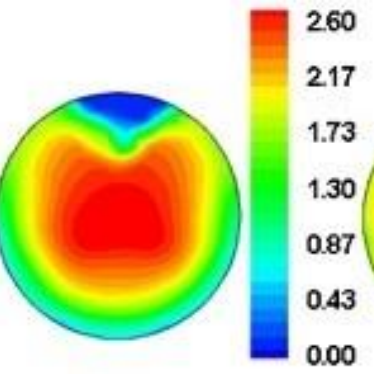

(b) (c)

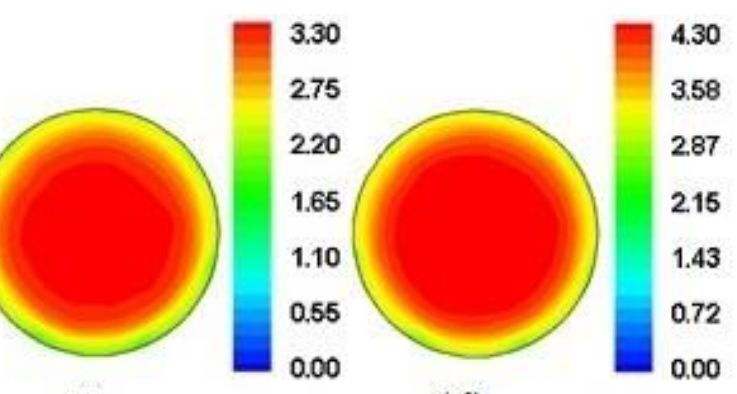

(d)

Figure 7. HSPL velocity contours at $C_{v f}=20 \%$, (a) $V_{m f}=1 \mathrm{~ms}^{-1}$, (b) $V_{m f}=2 \mathrm{~ms}^{-1}$, (c) $V_{m f}=3 \mathrm{~ms}^{-1}$, and (d) $V_{m f}=4 \mathrm{~ms}^{-1}$.

\section{VSPL Solid Concentration Contours}

Figure 8 depicts the solid concentration contours at the outlet of VSPL at solid concentration, $C_{v f}=10 \%$ (by volume) for different mean flow velocity range, $V_{m f}=1-4 \mathrm{~ms}^{-1}$. It has been discovered that the maximum solid concentration zone is situated close to the pipe wall and is least at the center of the pipe line for all chosen range of velocity and solid concentration. At low mean flow velocity, $V_{m f}=1 \mathrm{~ms}^{-1}$ the solid concentration zone around the center of the pipeline is maximum as portrayed in the Figure 8(a). However, as the velocity increment passed the $1 \mathrm{~ms}^{-1}$ the solid concentration zone shifts towards the pipe wall as depicted in Figure 8(a-c). Similarly comparable effect can be seen at solid concentration, $C_{v f}=20 \%$ for the chosen mean flow velocity range, $V_{m f}=1-4 \mathrm{~ms}^{-1}$ as depicted in the Figure 9 (a-d). The shifting of solid particulates towards the pipe wall is due to the dominating effect of viscous forces near the pipe wall.

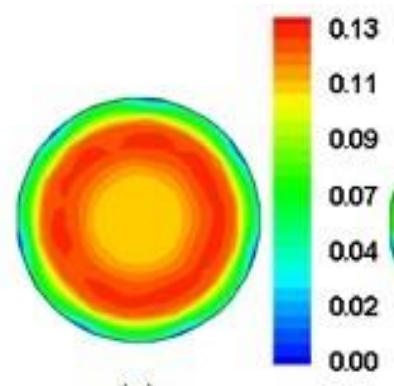

(a)

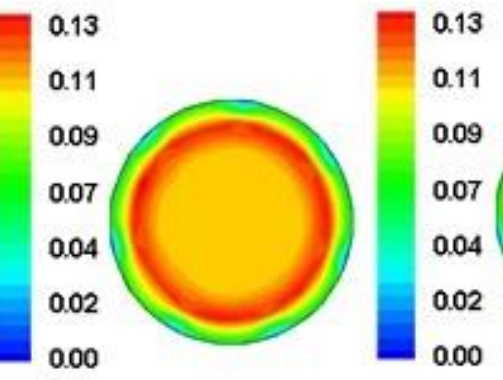

(b)

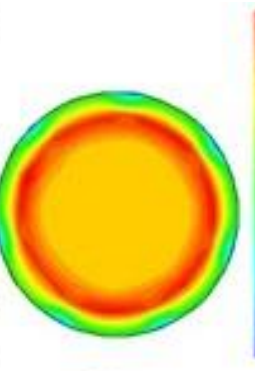

(c)

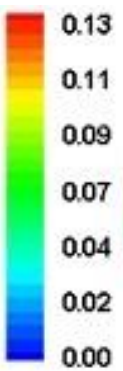

0.00

Figure 8. VSPL solid concentration contours at $C_{v f}=10 \%$, (a) $V_{m f}=1 \mathrm{~ms}^{-1}$, (b) $V_{m f}=2 \mathrm{~ms}^{-1}$, (c) $V_{m f}=3 \mathrm{~ms}^{-1}$, and (d) $V_{m f}=4 \mathrm{~ms}^{-1}$.

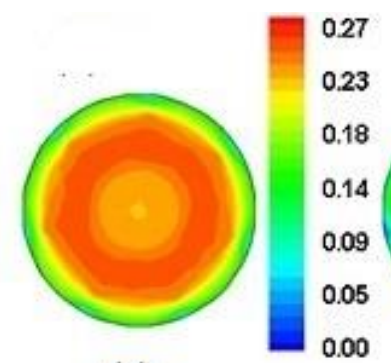

(a)

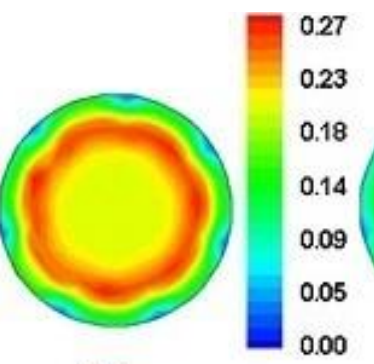

(b) (c)

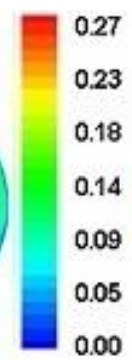

c) (d)

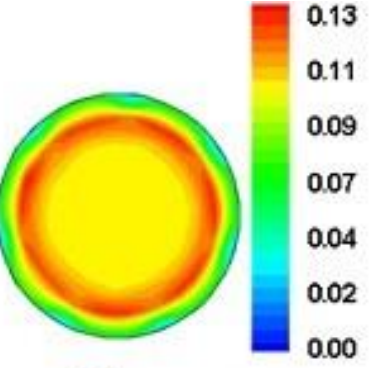

Figure 9. VSPL solid concentration contours at $C_{v f}=20 \%$, (a) $V_{m f}=1 \mathrm{~ms}^{-1}$, (b) $V_{m f}=2 \mathrm{~ms}^{-1}$, (c) $V_{m f}=3 \mathrm{~ms}^{-1}$, and (d) $V_{m f}=4 \mathrm{~ms}^{-1}$.

\section{VSPL Velocity Contours}

Figure 10 depicts the solid velocity contours at the outlet of VSPL at solid concentration, $C_{v f}=10 \%$ (by volume) for different mean flow velocity range, $V_{m f}=1-4 \mathrm{~ms}^{-1}$. It has been found that the solids exhibit maximum velocity at the center of the pipeline at all velocity range for the given solid concentration. Moreover, the velocity contours are symmetrical about the center of the pipeline at all mean flow velocities as portrayed in the Figure 10(a-d). Furthermore, 
the likewise comparable effect can be seen at solid concentration, $C_{v f}=20 \%$ for the chosen mean flow velocity range, $V_{m f}$ $=1-4 \mathrm{~ms}^{-1}$ as depicted in the Figure 11(a-d). The velocity contours are symmetrical because as the velocity and solid concentration increases the momentum exchange between the solid particulates increases, which cause the solid-solid and solid -wall interaction and enhance the turbulence blending of slurry flow in pipeline. In this way, solid particulates at the pipe center exhibits maximum velocity and the solid particulates, which are near to the pipe wall exhibits less velocity due to viscous effect.

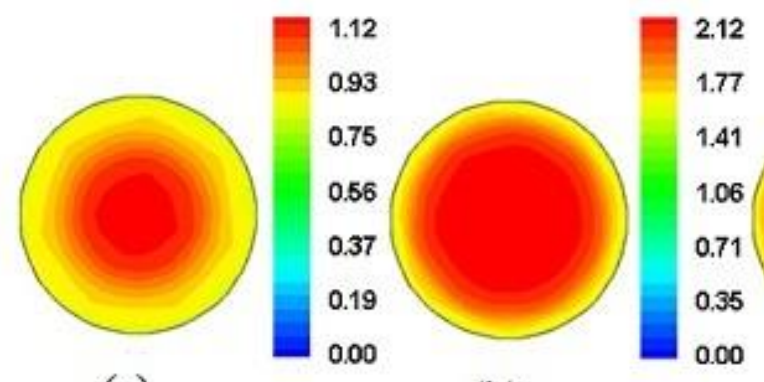

(a) (b)
00

(c)

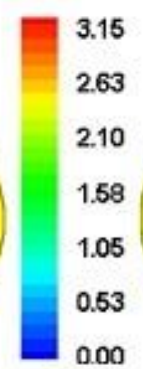

0.00

(c)

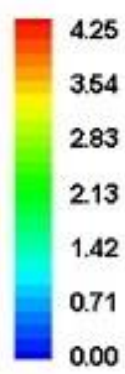

(d)

Figure 10. VSPL velocity contours at $C_{v f}=10 \%$ for (a) $V_{m f}=1 \mathrm{~ms}^{-1}$, (b) $V_{m f}=2 \mathrm{~ms}^{-1}$, (c) $V_{m f}=3 \mathrm{~ms}^{-1}$, and (d) $V_{m f}=4 \mathrm{~ms}^{-1}$.

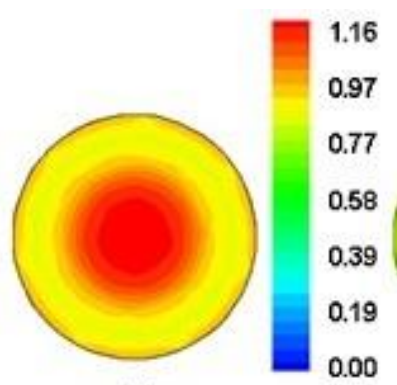

(a)

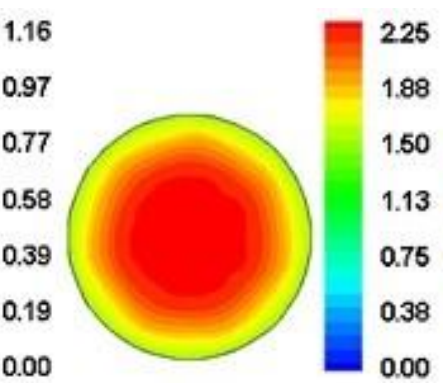

(b)

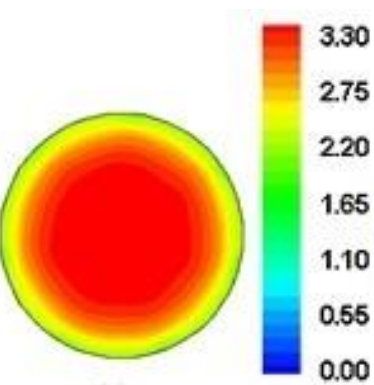

(c)

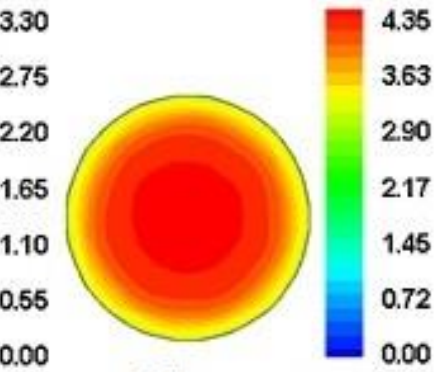

(d)

Figure 11. VSPL velocity contours at $C_{v f}=20 \%$ for (a) $V_{m f}=1 \mathrm{~ms}^{-1}$, (b) $V_{m f}=2 \mathrm{~ms}^{-1}$, (c) $V_{m f}=3 \mathrm{~ms}^{-1}$, and (d) $V_{m f}=4 \mathrm{~ms}^{-1}$.

\section{HSPL Solid Concentration Profile}

Figure12(a-d) portrays the solid concentration profile in HSPL in $x y$ plane at $x=3.7 \mathrm{~m}$ from pipe inlet, at different mean flow velocity range, $V_{m f}=1-4 \mathrm{~ms}^{-1}$ and solid concentration range, $C_{v f}=10-20 \%$. The findings show that the solid concentration is maximum at the pipe bottom and afterward decreases from bottom to top of the pipeline at all mean flow velocity and solid efflux concentration range.

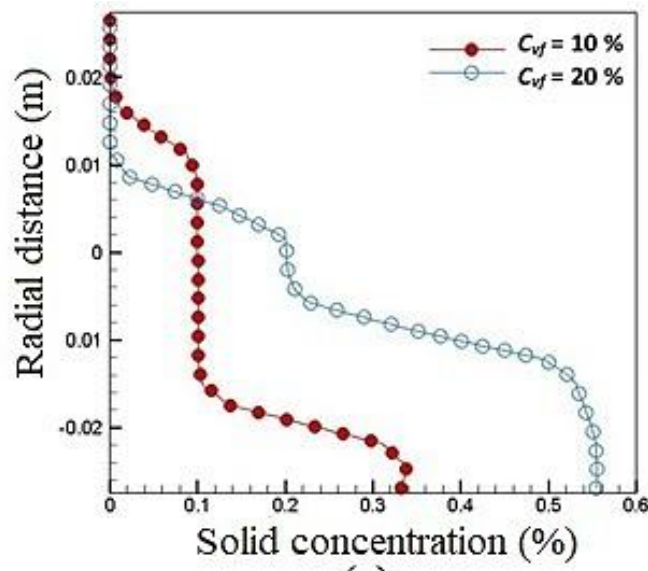

(a)

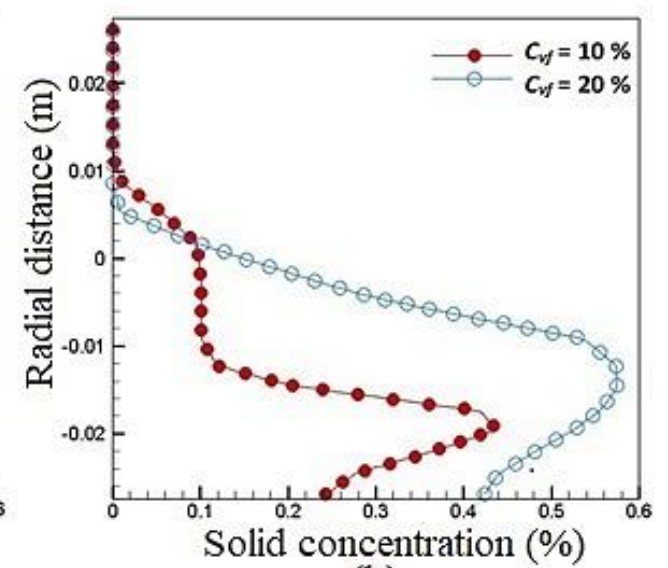

(b) 


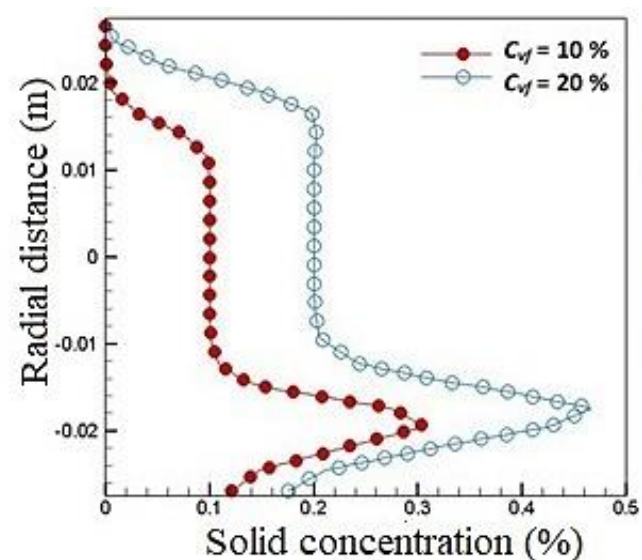

(c)

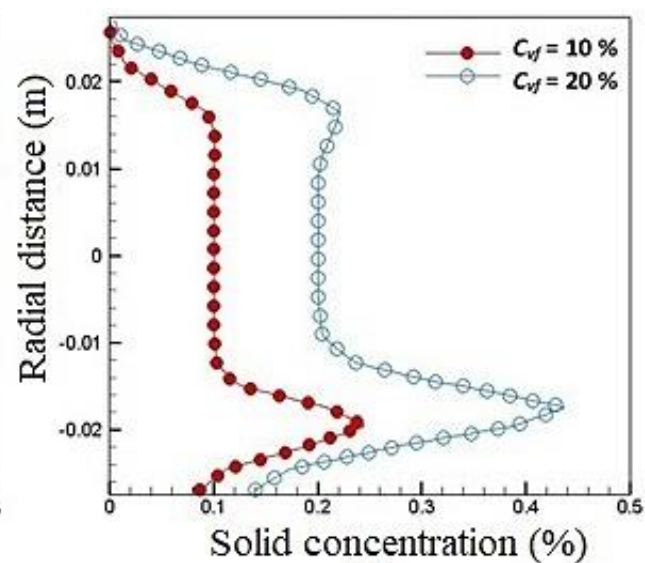

(d)

Figure 12. HSPL solid concentration profile at $C_{v f}=10-20 \%$, (a) $V_{m f}=1 \mathrm{~ms}^{-1}$, (b) $V_{m f}=2 \mathrm{~ms}^{-1}$, (c) $V_{m f}=3 \mathrm{~ms}^{-1}$, and (d) $V_{m f}=4 \mathrm{~ms}^{-1}$.

\section{HSPL Velocity Profile}

Figure 13(a-d) portrays the solid velocity profile in $x y$ plane at $x=3.7 \mathrm{~m}$ from the pipe inlet at solid concentration, $C_{v f}=10-20 \%$ for different mean flow velocity range, $V_{m f}=1-4 \mathrm{~ms}^{-1}$. It has been found that solid particulates exhibit maximum velocity at the center of the pipeline and least at the pipe wall. The velocity profile is flatten in nature at $C_{v f}=$ $10 \%$ for all mean flow velocity range. However, at low mean flow velocity, $V_{m f}=1-2 \mathrm{~ms}^{-1}$, the velocity profile at $C_{v f}=$ $20 \%$ is not flatten in nature as portrayed in the Figure 13(a-b).

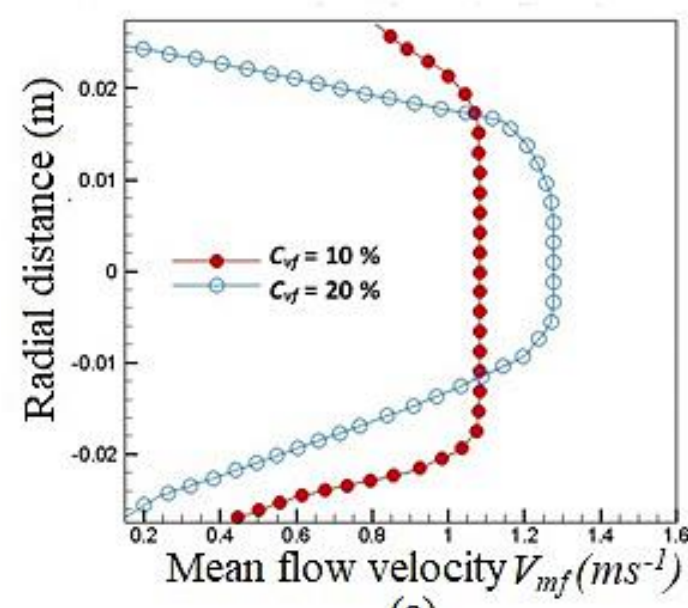

(a)

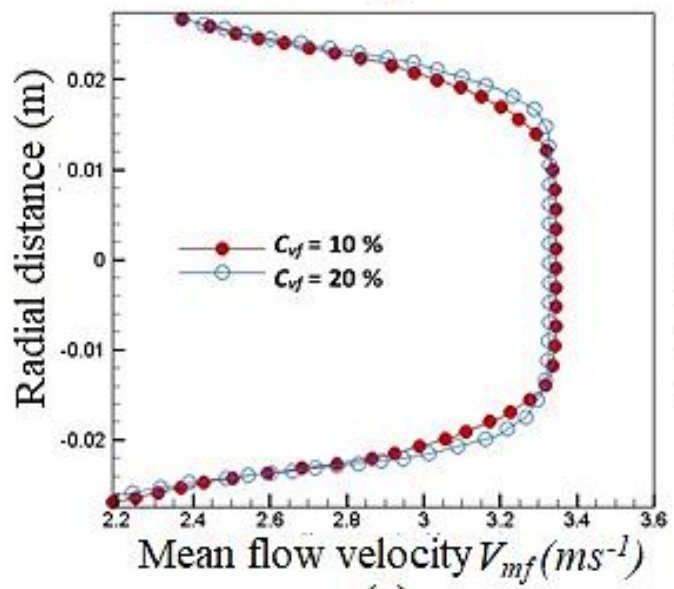

(c)

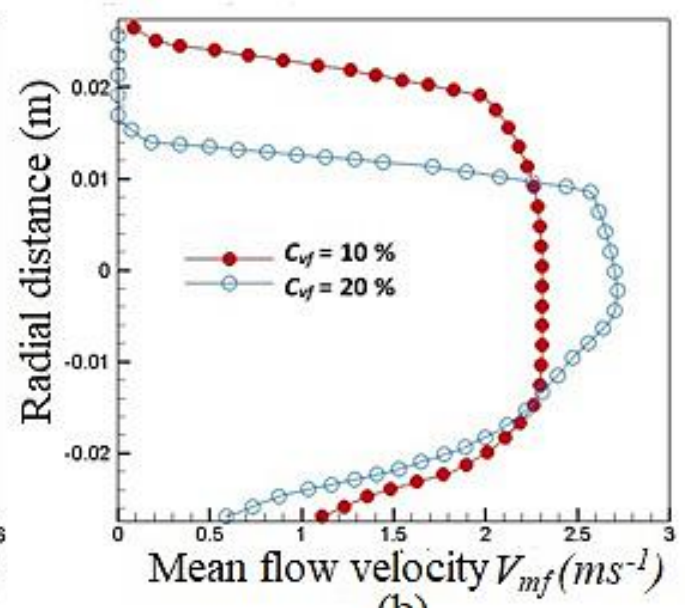

(b)

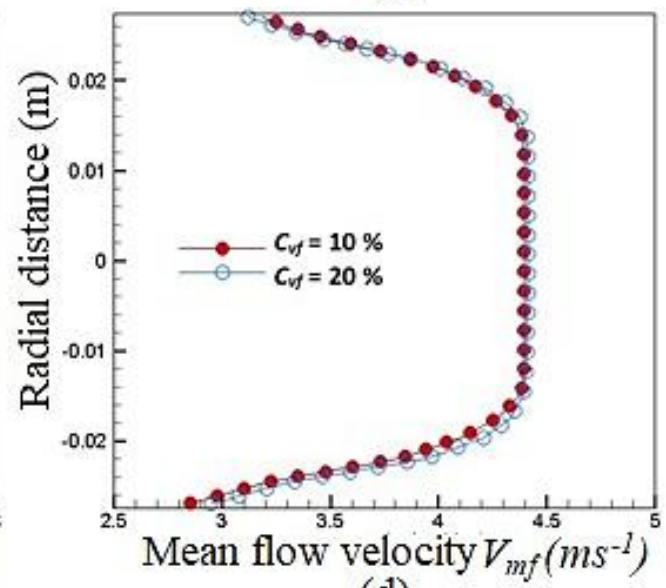

(d)

Figure 13. HSPL velocity profile at $C_{v f}=10-20 \%$, (a) $V_{m f}=1 \mathrm{~ms}^{-1}$, (b) $V_{m f}=2 \mathrm{~ms}^{-1}$, (c) $V_{m f}=3 \mathrm{~ms}^{-1}$, and (d) $V_{m f}=4 \mathrm{~ms}^{-1}$. 


\section{VSPL Solid Concentration Profile}

Figure 14(a-d) delineates the solid concentration profile in VSPL in $x y$ plane at $x=3.7 \mathrm{~m}$ from the pipe inlet at solid concentration, $C_{v f}=10-20 \%$ for mean flow velocity range, $V_{m f}=1-4 \mathrm{~ms}^{-1}$. The trend of solid concentration dissemination in VSPL is not quite the same as HSPL. It has been found that the solid concentration is minimum at the center of the pipeline and is maximum closer to the pipe wall at all mean flow velocity and solid efflux concentration.

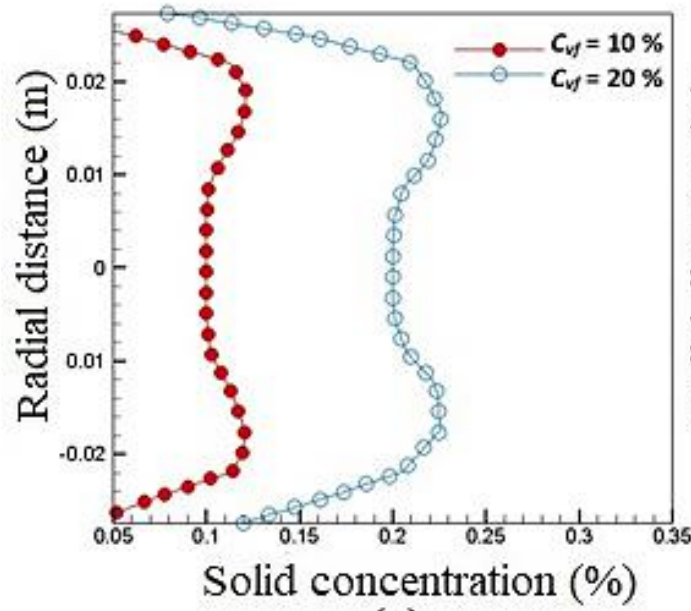

(a)

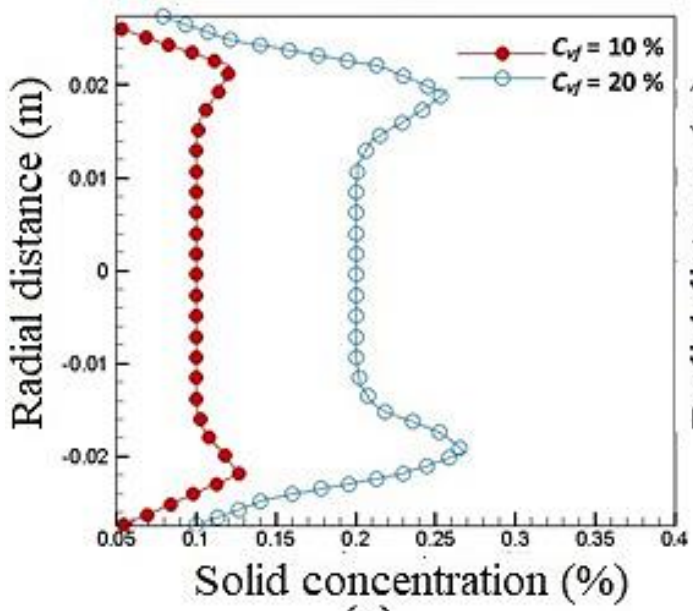

(c)

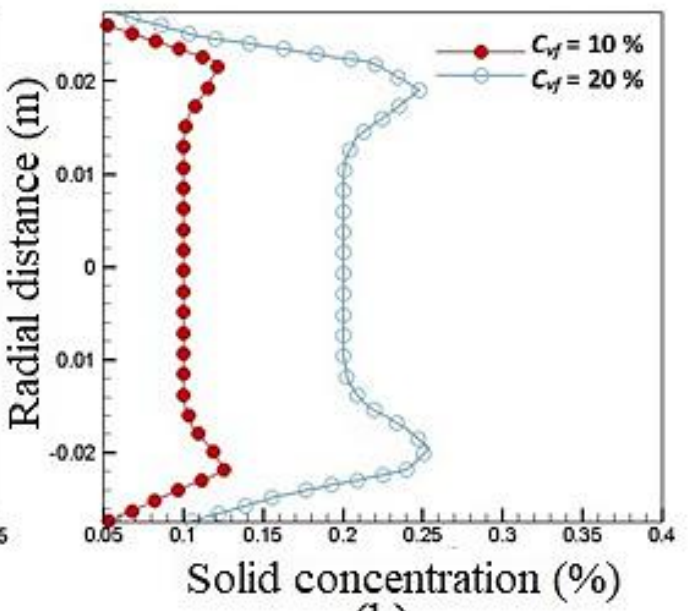

(b)

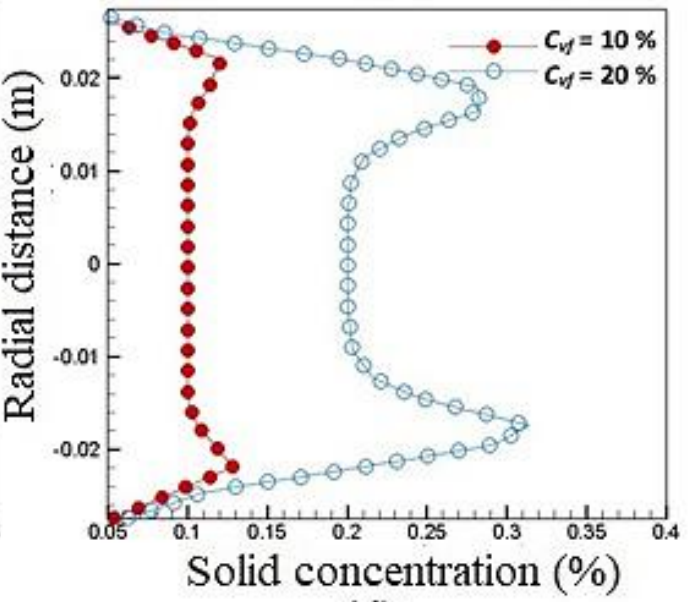

(d)

Figure 14. VSPL solid concentration profile at $C_{v f}=10-20 \%$, (a) $V_{m f}=1 \mathrm{~ms}^{-1}$, (b) $V_{m f}=2 \mathrm{~ms}^{-1}$, (c) $V_{m f}=3 \mathrm{~ms}^{-1}$, and (d) $V_{m f}=4 \mathrm{~ms}^{-1}$.

\section{VSPL Velocity Profile}

Figure $15(\mathrm{a}-\mathrm{d})$ depicts the velocity profile in $x y$ plane at $x=3.7 \mathrm{~m}$ from the pipe inlet at solid concentration, $C_{v f}=10$ $-20 \%$ for different velocity, $V_{m f}=1-4 \mathrm{~ms}^{-1}$. It has been found that solid particulates exhibit maximum velocity at the center of the pipeline and their profile is flatten in nature at all mean flow velocity and solid concentration except at $V_{m f}=4 \mathrm{~ms}^{-}$ ${ }^{1}$ and $C_{v f}=20 \%$ as depicted in the Figure $15(\mathrm{a}-\mathrm{d})$. The velocity profile turns to parabolic at $C_{v f}=20 \%$ and $V_{m f}=4 \mathrm{~ms}^{-1}$ due to increased turbulence blending as depicted in the Figure 15(d). 


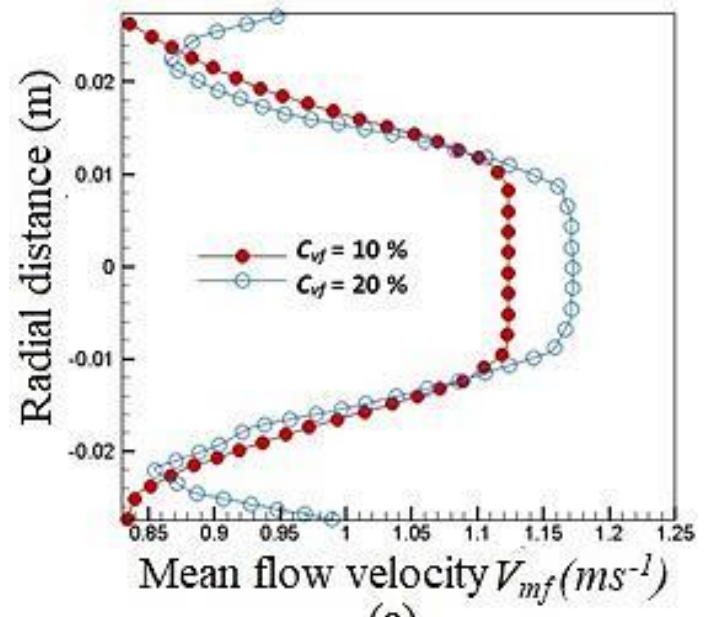

(a)

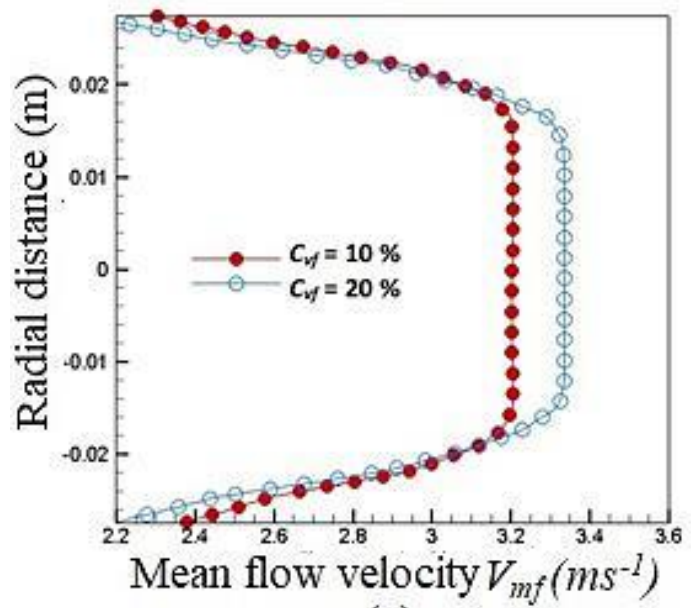

(c)

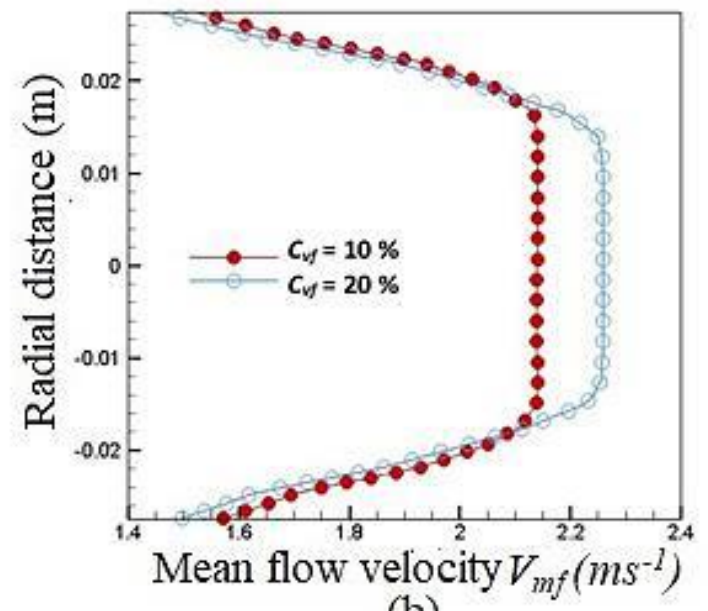

(b)

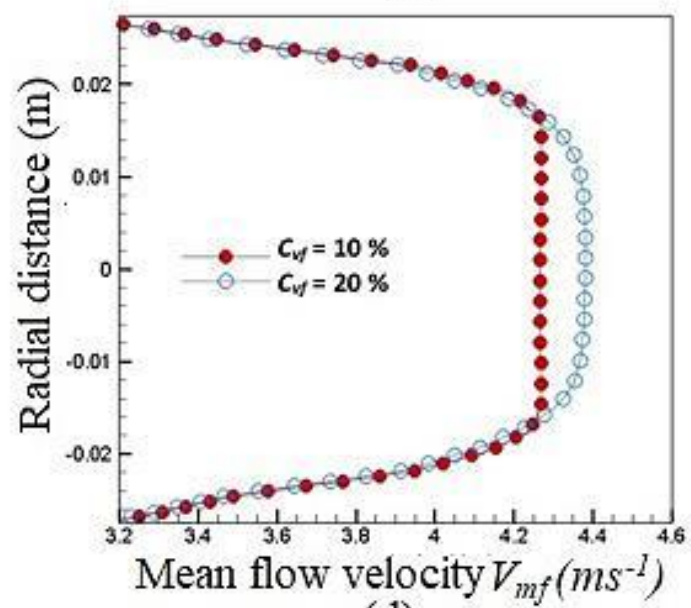

(d)

Figure 15. VSPL velocity profile at $C_{v f}=10-20 \%$, (a) $V_{m f}=1 \mathrm{~ms}^{-1}$, (b) $V_{m f}=2 \mathrm{~ms}^{-1}$, (c) $V_{m f}=3 \mathrm{~ms}^{-1}$, and (d) $V_{m f}=4 \mathrm{~ms}^{-1}$.

\section{Pressure Drop in HSPL and VSPL}

Figure 16(a-b) depicts the pressure drop variation in horizontal and vertical slurry pipeline for solid concentration, $C_{v f}$ $=10-20 \%$ and at different mean flow velocity range, $V_{m f}=1-4 \mathrm{~ms}^{-1}$. It has been found that the pressure drop increases at all velocity and solid concentration in both HSPL and VSPL. The pressure drop in the VSPL is found higher than the pressure drop in HSPL for chosen velocity and solid concentration range.

The percentage change in pressure drop in VSPL and HSPL is shown in the Table 1. It is found that the percentage change in pressure drop diminishes with increment in mean flow velocity for chosen solid concentration range. 


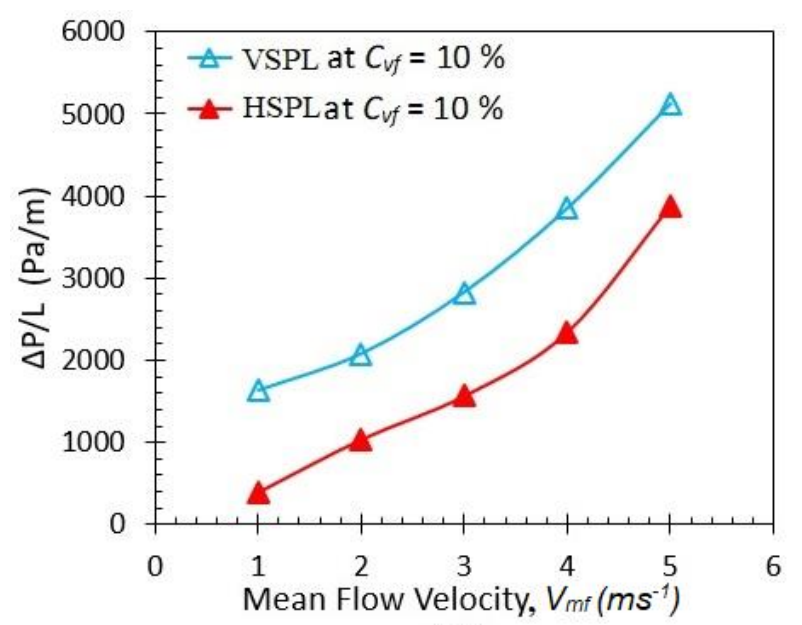

(a)

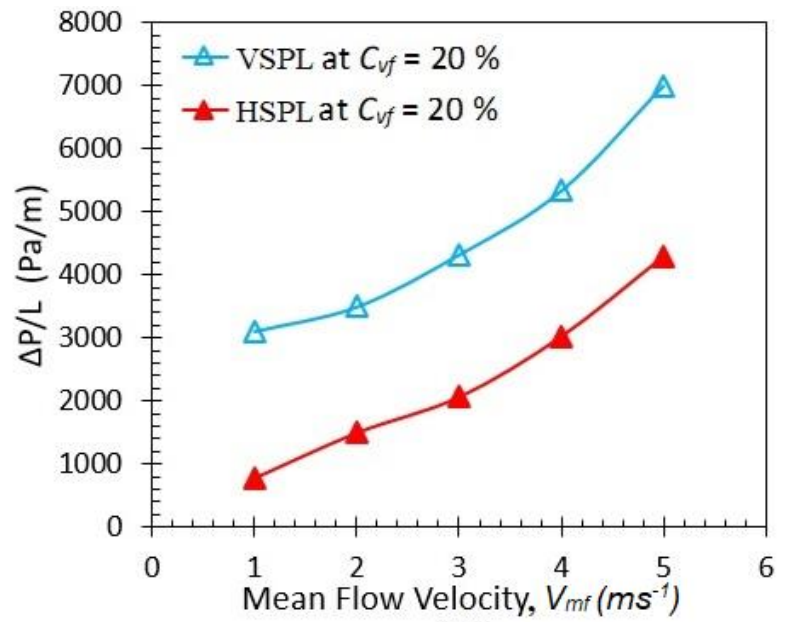

(b)

Figure 16. Pressure drop variation with mean flow velocity in HSPL and VSPL at solid concentration at (a) $C_{v f}=10 \%$ and (b) $C_{v f}=20 \%$.

Table 1. Pressure drop in VSPL and HSPL.

\begin{tabular}{ccccccc}
\hline $\begin{array}{c}\Delta \mathrm{P} / \mathrm{L} / \mathrm{L} \text { in VSPL } \\
\text { at } C_{v f}=10 \%\end{array}$ & $\begin{array}{c}\Delta \mathrm{P} / \mathrm{L} \text { in HSPL } \\
\text { at } C_{v f}=10 \%\end{array}$ & $\begin{array}{c}\Delta \mathrm{P} / \mathrm{L} \text { in VSPL } \\
\text { at } C_{v f}=20 \%\end{array}$ & $\begin{array}{c}\Delta \mathrm{P} / \mathrm{L} \text { in } \\
\mathrm{HSPL} \text { at } C_{v f}= \\
20 \%\end{array}$ & $\begin{array}{c}\text { Change in } \\
\Delta \mathrm{P} / \mathrm{L} \text { at } \\
C_{v f}=10 \%\end{array}$ & $\begin{array}{c}\text { Change in } \\
V_{m f} / \mathrm{P} \text { at } \\
C_{v f}=20 \%\end{array}$ \\
\hline 1 & $1,632.632$ & 398.0952 & $3,112.895$ & 782.9384 & $75.61 \%$ & $74.84 \%$ \\
2 & $2,079.211$ & $1,041.706$ & $3,501.316$ & $1,500.000$ & $49.89 \%$ & $57.15 \%$ \\
3 & $2,829.211$ & $1,572.512$ & $4,327.105$ & $2,065.403$ & $44.41 \%$ & $52.27 \%$ \\
4 & $3,850.263$ & $2,348.815$ & $5,341.579$ & $3,023.697$ & $38.99 \%$ & $43.39 \%$ \\
5 & $5,120.526$ & $3,887.204$ & $7,007.105$ & $4,290.995$ & $24.08 \%$ & $38.76 \%$ \\
\hline
\end{tabular}

\section{MODEL VALIDATION}

The developed computational model for HSPL is validated with the accessible experimental data [3] at $C_{v f}=10 \%$ and $20 \%$ as depicted in the Figure 17(a) and (b), respectively. It has been found that the present computational model gives the satisfactory outcomes and is synchronized with the experimental data. The anticipated pressure drop in VSPL is found to pursue a similar pattern as with HSPL but higher in magnitude for all chosen velocity and solid concentration range. Therefore, the finding of slurry flow attributes, by utilizing the computational model for HSPL and VSPL is precise and accurate.

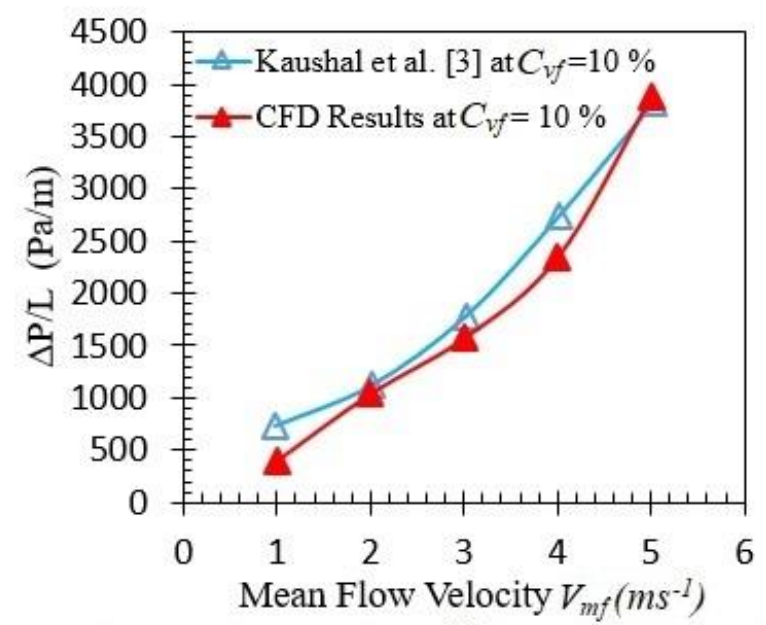

(a)

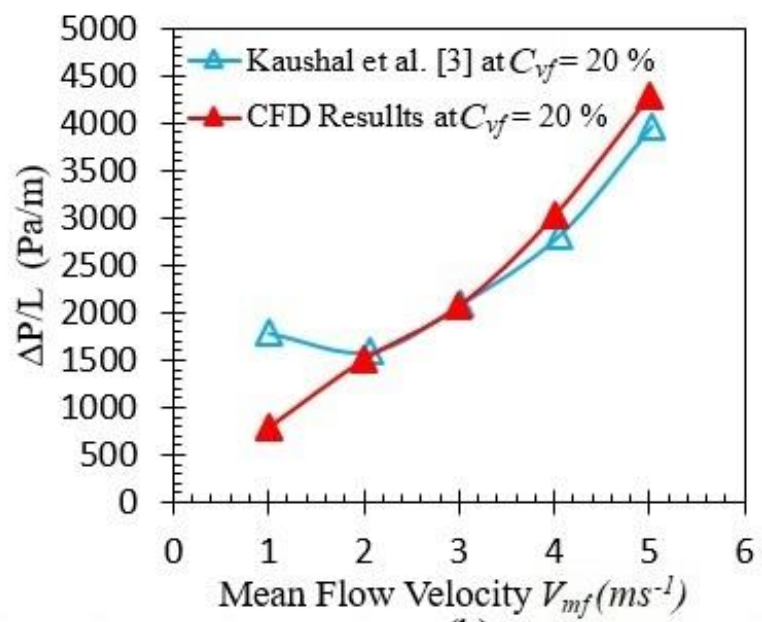

(b)

Figure 17. Validation of results for HSPL at solid concentration (a) $C_{v f}=10 \%$ and (b) $C_{v f}=20 \%$. 


\section{CONCLUSIONS}

Based on the comparative analysis of computational model for HSPL and VSPL at different velocities and solid concentrations, the following conclusions have been drawn:

- It is found that Eulerian model using RNG $k-\varepsilon$ turbulence closure gives the more appropriate and meticulous predictions of the pressure drop in the HSPL and VSPL for chosen range of velocity and solid concentration.

- The high concentration zone is located closer to the pipe bottom in HSPL and solid concentration decreases from bottom to top of the pipeline. However, the high solid concentration zone is located alongside the pipe wall in VSPL and is minimum at the center of the pipeline.

- The solid exhibits maximum velocity at the center of the pipeline and least nearby the pipe wall in both HSPL and VSPL due to viscous effect near the wall.

- The velocity contours in HSPL are asymmetrical at low mean flow velocity and turn into symmetrical at higher mean flow velocity. Nevertheless, the velocity contours in VSPL are symmetrical at all mean flow velocity and solid efflux concentration.

- It is found that velocity profile is flatten in nature at low velocity for chosen solid concentration and it tends to parabolic at high velocity and high solid concentration due to increased momentum exchange and turbulence blending in both slurry pipeline.

- The pressure drop increases for both HSPL and VSPL at all velocity and solid concentration range. The pressure drop in VSPL is found higher than the pressure drop in HSPL. The anticipated pressure drop results for HSPL are observed to be in synchronism with the available experiment data. Additionally, the anticipated pressure drop in VSPL is found to pursue the same pattern as with HSPL however higher in magnitudes for all chosen velocity and solid concentration range.

In the present study, it is concluded that VSPL exhibits more pressure drop as compared to the HSPL and thus leads to more power and energy requirement for the slurry flow through it. Therefore, it is recommended that there should be minimum vertical fittings in the design of economical and efficient slurry pipeline framework to minimize the pressure losses. The work can further be extended by considering different solid particulate sizes through vertical pipeline for finding erosion wear rate and slurry flow characteristics.

\section{REFERENCES}

[1] V. Matousek, "Pressure drops and flow patterns in sand-mixture pipes," Exp. Therm. Fluid Sci., vol. 26, no. 6-7, pp. 693-702, 2002, doi: 10.1016/S0894-1777(02)00176-0.

[2] M. Kraft, "Modelling of particulate processes," KONA Powder Part. J., vol. 23, no. March, pp. 18-35, 2005, doi: 10.14356/kona.2005007.

[3] D. R. Kaushal and Y. Tomita, "Experimental investigation for near-wall lift of coarser particles in slurry pipeline using $\gamma$-ray densitometer," Powder Technol., vol. 172, no. 3, pp. 177-187, 2007, doi: 10.1016/j.powtec.2006.11.020.

[4] U. Kumar, S. N. Singh, and V. Seshadri, "Experimental investigation on pressure drop characteristics of bi-modal slurry flow in a straight horizontal pipe," International Journal of Scientific \& Engineering Research, vol. 6, no. 11, pp. 153-158, 2015.

[5] V. Matoušek, "Pipe-wall friction in vertical sand-slurry flows," Part. Sci. Technol., vol. 27, no. 5, pp. 456-468, 2009, doi: 10.1080/02726350903133179.

[6] C. X. Lin and M. A. Ebadian, "A numerical study of developing slurry flow in the entrance region of a horizontal pipe," Comput. Fluids, vol. 37, no. 8, pp. 965-974, 2008, doi: 10.1016/j.compfluid.2007.10.008.

[7] S. Chandel, V. Seshadri, and S. N. Singh, "Effect of additive on pressure drop and rheological characteristics of fly ash slurry at high concentration,” Part. Sci. Technol., vol. 27, no. 3, pp. 271-284, 2009, doi: 10.1080/02726350902922036.

[8] S. Chandel, S. N. Singh, and V. Seshadri, "Iaast 1-9," vol. 1, no. JUNE, pp. 1-9, 2010.

[9] H. Naik, M. Mishra, and K. Rao, "Influence of Chemical Reagents on Rheological Properties of Fly Ash-Water Slurry at Varying Temperature Environment," Coal Combust. Gasif. Prod., vol. 3, no. 1, pp. 83-93, 2011, doi: 10.4177/ccgp-d-1100015.1.

[10] P. K. Senapati, B. K. Mishra, and A. Parida, "Analysis of friction mechanism and homogeneity of suspended load for high concentration fly ash \& bottom ash mixture slurry using rheological and pipeline experimental data," Powder Technol., vol. 250, pp. 154-163, 2013, doi: 10.1016/j.powtec.2013.10.014.

[11] Y. Y. Jiang and P. Zhang, "Numerical investigation of slush nitrogen flow in a horizontal pipe," Chem. Eng. Sci., vol. 73, pp. 169-180, 2012, doi: 10.1016/j.ces.2012.01.027.

[12] D. R. Kaushal, T. Thinglas, Y. Tomita, S. Kuchii, and H. Tsukamoto, "CFD modeling for pipeline flow of fine particles at high concentration,” Int. J. Multiph. Flow, vol. 43, pp. 85-100, 2012, doi: 10.1016/j.ijmultiphaseflow.2012.03.005.

[13] D. R. Kaushal, A. Kumar, Y. Tomita, S. Kuchii, and H. Tsukamoto, "Flow of mono-dispersed particles through horizontal bend," Int. J. Multiph. Flow, vol. 52, pp. 71-91, 2013, doi: 10.1016/j.ijmultiphaseflow.2012.12.009.

[14] I. E.-S. and K. E.-N. Tamer Nabil, "Sand-water slurry flow modelling in a horizontal pipeline solid-liquid slurry flow CFD model eulerian model," Int. Water Technol. J., vol. 4, no. March, pp. 1-17, 2014. 
[15] R. Silva, F. A. P. Garcia, P. M. G. M. Faia, and M. G. Rasteiro, "Settling suspensions flow modelling: A review," KONA Powder Part. J., no. 32, pp. 41-56, 2015, doi: 10.14356/kona.2015009.

[16] M. K. Gopaliya and D. R. Kaushal, "Analysis of effect of grain size on various parameters of slurry flow through pipeline using CFD,” Part. Sci. Technol., vol. 33, no. 4, pp. 369-384, 2015, doi: 10.1080/02726351.2014.971988.

[17] G. K. Pani, P. Rath, R. Barik, and P. K. Senapati, "The effect of selective additives on the rheological behavior of power plant ash slurry," Part. Sci. Technol., vol. 33, no. 4, pp. 418-422, 2015, doi: 10.1080/02726351.2014.990657.

[18] K. M. Assefa and D. R. Kaushal, "Experimental study on the rheological behaviour of coal ash slurries," J. Hydrol. Hydromechanics, vol. 63, no. 4, pp. 303-310, 2015, doi: 10.1515/johh-2015-0029.

[19] M. Swamy, N. G. Díez, and A. Twerda, "Numerical modelling of the slurry flow in pipelines and prediction of flow regimes," Comput. Methods Multiph. Flow VIII, vol. 1, pp. 311-322, 2015, doi: 10.2495/mpf150271.

[20] D. Wu, B. Yang, and Y. Liu, "Pressure drop in loop pipe flow of fresh cemented coal gangue-fly ash slurry: Experiment and simulation," Adv. Powder Technol., vol. 26, no. 3, pp. 920-927, 2015, doi: 10.1016/j.apt.2015.03.009.

[21] G. V. Messa and S. Malavasi, "Improvements in the numerical prediction of fully-suspended slurry flow in horizontal pipes," Powder Technol., vol. 270, no. Part A, pp. 358-367, 2015, doi: 10.1016/j.powtec.2014.10.027.

[22] M. Kumar Gopaliya and D. R. Kaushal, "Modeling of sand-water slurry flow through horizontal pipe using CFD," J. Hydrol. Hydromechanics, vol. 64, no. 3, pp. 261-272, 2016, doi: 10.1515/johh-2016-0027.

[23] T. N. Ofei and A. Y. Ismail, "Eulerian-Eulerian Simulation of Particle-Liquid Slurry Flow in Horizontal Pipe," J. Pet. Eng., vol. 2016, pp. 1-10, 2016, doi: 10.1155/2016/5743471.

[24] W. Peng and X. Cao, "Numerical simulation of solid particle erosion in pipe bends for liquid-solid flow," Powder Technol., vol. 294, pp. 266-279, 2016, doi: 10.1016/j.powtec.2016.02.030.

[25] D. R. Kaushal, A. Kumar, Y. Tomita, S. Kuchii, and H. Tsukamoto, "Flow of Bi-modal slurry through horizontal bend," KONA Powder Part. J., vol. 2017, no. 34, pp. 258-274, 2017, doi: 10.14356/kona.2017016.

[26] K. M. Assefa and D. R. Kaushal, "A new model for the viscosity of highly concentrated multi-sized particulate Bingham slurries,” Part. Sci. Technol., vol. 35, no. 1, pp. 77-85, 2017, doi: 10.1080/02726351.2015.1131789.

[27] A. K. Melorie and D. Raj Kaushal, "Experimental investigations of the effect of chemical additives on the rheological properties of highly concentrated iron ore slurries," KONA Powder Part. J., vol. 2018, no. 35, pp. 186-199, 2018, doi: 10.14356/kona.2018001.

[28] R. Naveh, N. M. Tripathi, and H. Kalman, "Experimental pressure drop analysis for horizontal dilute phase particle-fluid flows," Powder Technol., vol. 321, pp. 355-368, 2017, doi: 10.1016/j.powtec.2017.08.029.

[29] J. P. Singh, S. Kumar, and S. K. Mohapatra, "Modelling of two phase solid-liquid flow in horizontal pipe using computational fluid dynamics technique," Int. J. Hydrogen Energy, vol. 42, no. 31, pp. 20133-20137, 2017, doi: 10.1016/j.ijhydene.2017.06.060.

[30] R. A. Sultan, M. A. Rahman, S. Rushd, S. Zendehboudi, and V. C. Kelessidis, "Validation of CFD model of multiphase flow through pipeline and annular geometries," Part. Sci. Technol., vol. 37, no. 6, pp. 685-697, 2019, doi: $10.1080 / 02726351.2018 .1435594$.

[31] M. Tran, Z. Memon, A. Saieed, W. Pao, and F. Hashim, "Numerical simulation of two-phase separation in T-junction with experimental validation,” J. Mech. Eng. Sci., vol. 12, no. 4, pp. 4216-4230, 2018, doi: 10.15282/jmes.12.4.2018.17.0363.

[32] O. Parkash, A. Kumar, and B. S. Sikarwar, "CFD modeling of commercial slurry flow through horizontal pipeline," In Advances in Interdisciplinary Engineering, Springer, Singapore, pp. 153-162, 2019.

[33] S. U. Ahmed, R. Arora, and O. Parkash, "Flow characteristics of multiphase glass beads-water slurry through horizontal pipeline using computational fluid dynamics," Int. J. Automot. Mech. Eng., vol. 16, no. 2, 2019, doi: 10.15282/ijame.16.2.2019.10.0497.

[34] A. Bouaffane and K. Talbi, "Thermal study of fluid flow inside an annular pipe filled with porous media under local thermal non-equilibrium condition," vol. 18, no. 1, pp. 59-66, 2011.

[35] O. Parkash and R. Arora, "Flow characterization of multi-phase particulate slurry in thermal power plants using computational fluid dynamics," J. Therm. Eng., vol. 6, no. 1, pp. 188-203, 2020, doi: 10.18186/THERMAL.672785.

[36] S. Ahmed, R. Arora, and O. Parkash, "Prediction of flow parameters of glass beads-water slurry flow through horizontal pipeline using computational fluid dynamics," Jordan J. Mech. Ind. Eng., vol. 12, no. 3, 2019.

[37] S. Ahmed, R. Arora, and O. Parkash, "Numerical investigations on flow characteristics of sand-water slurry through horizontal pipeline using computational fluid dynamics," J. Therm. Eng., vol. 6, no. 2, pp. 128-139, 2020, doi: 10.18186/thermal.729205. 